\title{
Why did she leave? Development of working alliance in a case of psychotherapy for depression
}

\author{
Petr Doležal, Michal Čevelíček, Tomáš Řiháček, Jan Roubal, Roman Hytych, Lucia Ukropová \\ Centre for Psychotherapy Research, Department of Psychology, Faculty of Social Studies, Masaryk University, Brno, Czech Republic
}

\begin{abstract}
The present case study aims to explore the unfolding of the working alliance in a case that ended with the client dropping out of psychotherapy, unilaterally cutting off her contact with the therapist. However, both quantitative and qualitative outcome assessments strongly suggested that. An analysis of session transcripts, the Client Change Interview, and the Interpersonal Process Recall interviews for three selected sessions was used to analyze the development of the working alliance and its contribution to the dropout. This case study illustrates how the working alliance is constructed differently during the different phases of the therapeutic process. Specifically, the fruitful problem-solving in the first part of psychotherapy helped the client to improve her functioning. Yet this intervention seemed to exhaust its potential over time, and later the dyad had trouble finding another useful mode of interaction due to the interpersonal context, leading to more serious ruptures and, eventually, to the dropout. The findings are discussed in terms of therapist responsiveness and of its role in the continuous negotiation of the working alliance.
\end{abstract}

Key words: Depressive disorder; Evidence-based case study; Dropout; Responsiveness; Working alliance.

Correspondence: Petr Doležal, Centre for Psychotherapy Research, Department of Psychology, Faculty of Social Studies, Masaryk University, Jostova 10, 60200 Brno, Czech Republic.

Tel.: +420.736.134.138.

E-mail: pdolezal@mail.muni.cz

Citation: Doležal, P., Čevelíček, M., Řiháček, T., Roubal, J., Hytych, R., \& Ukropová, L. (2019). Why did she leave? Development of working alliance in a case of psychotherapy for depression. Research in Psychotherapy: Psychopathology, Process and Outcome, 22(2), 150-164. doi: 10.4081/ripppo.2019.354

Contributions: PD, manuscript drafting and revising, reference search, data analysis, data collection, research design planning; MČ, manuscript drafting and revising, research design planning, data collection, data analysis; Tř, manuscript revising, research design planning; JR, RH, manuscript revising, data analysis; LU, manuscript revising, data analysis, data collection, research design planning.

Conflict of interest: the authors declare no potential conflict of interest.

Funding: this study was supported by the Specific University Research Grant No. MUNI/A/1024/2016 provided by the Czech Ministry of Education, Youth, and Sports.

Received for publication: 30 November 2018.

Revision received: 28 February 2019.

Accepted for publication: 25 March 2019.

This work is licensed under a Creative Commons Attribution NonCommercial 4.0 License (CC BY-NC 4.0).

${ }^{\circ}$ Copyright: the Author(s), 2019

Licensee PAGEPress, Italy

Research in Psychotherapy:

Psychopathology, Process and Outcome 2019; 22:150-164

doi:10.4081/ripppo.2019.354

\section{Introduction}

Many randomized controlled trials have proven that psychotherapy is effective in the treatment of depressive disorders, displaying the same effect sizes as pharmacotherapy (Cuijpers, 2017). Yet, there is still room for improvement, because many clients have recurring symptoms or do not improve (Cuijpers, Ebert, Acarturk, Andersson, \& Cristea, 2016), many clients drop out of the treatment (Roos \& Werbart, 2013) and the research on mechanisms that lead to a change does not offer a clearcut empirical explanation for how psychotherapy works (Lemmens, Müller, Arntz, \& Huibers, 2016). Process-outcome research aims to help us better understand how to make psychotherapy more useful for people with depressive symptoms. The present study aims to contribute to the process-outcome research by presenting a systematic case study which explores mechanisms leading to a marked symptomatic change in psychotherapy of a client with depressive symptoms. At the same time, the study explores mechanisms leading to the dropout of the same client, who decided to leave the psychotherapy prematurely. As a result, the present study offers an opportunity to explore a case which could be evaluated either as a success, or as a failure, depending on our perspective.

Dropout is a serious issue in psychotherapy, as approximately $20-50 \%$ of clients leave treatment prematurely (Roos \& Werbart, 2013; Swift \& Greenberg, 2012). Roos and Werbart (2013) named various reasons for clients dropping out: not having enough information, validation and support from therapist; perceiving the psychotherapist as unsympathetic, passive and indifferent; assuming that 
the psychotherapy has not fulfilled clients' expectation; early symptom relief; and lack of improvement. At a more abstract level, reasons for dropout can be conceptualized as a cost-for-benefit analysis by clients who constantly weigh costs and benefits of therapy and try to balance them with demands of their lives (Swift, Greenberg, Whipple, \& Kominiak, 2012). The fact that a client drops out of the psychotherapy, however, does not always mean that the treatment was a failure. Often, psychotherapists do not find out why their clients haven't shown up for the next session, as they cannot ask the clients follow-up questions. The present study addresses this issue by presenting a case of a client who achieved significant symptomatic change in psychotherapy, but dropped out of the treatment anyways.

In the field of process-outcome research, common factors - the variables that predict outcomes across different psychotherapy approaches and diagnostic categories have an important place (Lambert, 2013). These factors can be used to explain both beneficial impacts and impediments, including dropout, in psychotherapy. The psychotherapeutic relationship is one of the common factors that is robustly associated with outcomes (CritsChristoph, Gibbons \& Mukherjee, 2013; Flückiger, Del Re, Wampold, \& Horvath, 2018). Multiple factors constitute the psychotherapeutic relationship, including the working alliance (Horvath, Del Re, Flückiger \& Symonds, 2011); affirmative behavior and expressive attunement among psychotherapists and clients (Barnicot, Wampold, \& Priebe, 2014); and repairs of ruptures in the alliance (Chen, Atzil-Slonim, Bar-Kalifa, HassonOhayon, \& Refaeli, 2016).

The working alliance is probably the most researched component of the therapeutic relationship, and it is useful in explaining the psychotherapy success (Horvath et al., 2011) and dropout (Sharf, Primavera, \& Diener, 2010) In his classic definition, Bordin (1979) defines the working alliance as the ability to collaborate on therapeutic tasks and goals, and the quality of the emotional bond between the client and the therapist. Safran and Muran (2006) have suggested that the advantage of Bordin's concept is the implicitly stated interdependence between technical and relational factors. This issue has been most recently picked up by Westerman and Muran (2017), who argue that we cannot properly understand the alliance's agreement about tasks, goals, and bond without characterizing the interpersonal process involved. The working alliance, in this perspective, is a configuration of tasks, goals, and bond quality that is specific to a therapeutic collaboration between a given client and therapist (Hatcher, 2010). This configuration cannot be reduced to the total amount of bond, task, and goal consensus.

Another conceptual issue pointed out by Safran and Muran $(2000,2006)$ is that an aggregate quantification of different working alliance factors cannot convey how the configuration of the working alliance in a specific thera- peutic relationship changes over time. In this view, the working alliance is a process of continuous negotiations between the psychotherapist and the client, rather than some constant quality the dyad needs to achieve for the interventions to work. Consequently, when we measure working alliance at two time points within the same psychotherapy case, the same measured value may refer to different working alliance configurations. One of these configurations might be helpful for the client, while the other configuration may lead to client dropping out of the psychotherapy.

When we consider the momentary configuration of a working alliance and how it changes over time, it becomes clear that condensing therapeutic relationships into a single evaluative dimension does violence to clinical conceptualizations of therapeutic relationships (Stiles \& Goldsmith, 2010, p. 55). This is a more general issue in psychotherapy process-outcome research, as this research tends to be superficial relative to the complexity of the actual interactions among clients and therapists that put process variables into action (Baldwin, Wampold, \& Imel, 2007). Research on psychotherapist responsiveness addresses these conceptual issues by exploring therapists' ability to notice the momentary client needs and the shifting configuration in the psychotherapeutic relationship and adapt their actions to it.

Responsiveness describes a psychotherapist's ability to perceive and flexibly react to clients' emotional states and needs, as well as their ability to use interpersonal skills and techniques to achieve psychotherapy goals (Hatcher, 2015). Responsive psychotherapists are aware of the subtle moment-to-moment processes that unfold in psychotherapy, while at the same time, they can see a broader picture of clients' lives (Kramer \& Stiles, 2015). This close attention paid by therapists guides them in deciding what to do - and when and how to do it - as new information emerges, and results in a high variability of therapeutic actions across cases and sessions. Hence, the psychotherapist and client need to renegotiate their relationship constantly, because once useful relationship configuration might later lose its potential.

We argue that capturing the complexity of alliance negotiations is essential if research results are to be clinically meaningful. Ackerman and Hilsenroth (2003) suggest using a combination of qualitative and quantitative methods to develop a clinically meaningful data integration. The evidence-based case study, meanwhile, has been proposed as a design that enables such an integration (Dattilio, Edwards, \& Fishman, 2010). Evidence-based case studies that combine a standardized process and outcome measures with a qualitative investigation of the process of change within psychotherapy may provide an insight into the interplay of a wide range of variables and the contextualized process of change (Carey \& Stiles, 2016). Systematic case studies are especially valuable if we aim to explore important and unexpected events such as drop out 
from psychotherapy contrasting with symptomatic improvement.

To demonstrate how such a surprising turn of events may be explained, we explore the psychotherapeutic alliance as it relates to the outcome in a case of psychotherapy for depression, using an evidence-based case study design. The study's goal is to place the outcome's qualitative and quantitative evaluation into the context of the therapeutic alliance development and to interconnect important process variables, explaining the positive symptomatic change and the client's premature psychotherapy termination. We argue that the unique configuration of the client/psychotherapist relationship in the present case led to the designated outcome. However, at the same time, the relationship's configuration contributed to the client's dropping out of this therapy. We focus on the nuances that resist a clear evaluation of this case as a success or a failure, and we use the conceptualization of the working alliance as a configuration shifting over time (Safran \& Muran, 2006) and the concept of responsiveness (Stiles, 2009) as a framework to help us understand the ambiguous nature of the therapeutic relationship in this specific case.

\section{Methods}

\section{The case}

The present case was a part of a larger study focusing on important moments identified by clients and psychotherapists in psychotherapy for depressive disorders. The case was selected because of its divergence from the expected pathway (McLeod, 2010, p. 38), as we usually do not expect cases with a good outcome to end in a client dropout. We propose that an exploration of such ambiguity is useful for promoting our understanding of the role of the working alliance in the psychotherapy process.

\section{The client}

The client was a 23-year-old female university student, who will be referred to as Ela in this study. Ela was experiencing anxiety and a depressed mood, which worsened three to four months before the therapy. She was partially financially dependent on her parents, and she had little experience with romantic relationships, having had one boyfriend at the age of 16 , and a narrow circle of friends. She reported no mental illnesses or addictions in her family. Her symptoms had a self-diagnosed onset at the age of 16 and had worsened since that time. Nevertheless, she had not sought any professional help before.

\section{The psychotherapist}

The psychotherapist was a 33-year-old female psychologist with psychodynamic training. She had eight years of practice in psychodynamic therapy and, at the time of the study, she worked at a family counseling center.
Psychodynamic psychotherapies emphasize the contribution of clients' interpersonal relationships and experiencing to their complaints. In the treatment, they use a continuum of supportive and interpretive psychotherapeutic interventions, which are theoretically grounded in the assumption that clients' problems stem from conflicting aspects within their self. Resolving this conflict then leads to the reduction of clients' complaints. Because in the present case, only 20 sessions were planned, we can consider this therapy to be short term, with some specifics in contrast to long-term psychodynamic psychotherapy. Short term psychodynamic therapy restricts intense affect mobilisation, psychotherapists should use a more active stance, put more emphasis on working with material from between the sessions and balance the use of interpretative and supportive interventions (Leichsenring \& Schauenburg, 2014). In short term therapies, it may be necessary to establish alliance early with special attention to establishing realistic goals and outlining the therapeutic rationale. The focus of the therapy should be maintained throughout the treatment. Due to the limited time, psychotherapists may not have enough time to work through potential vicious circles, including transference and countertransference enactments. Termination and its meaning for clients should be discussed (Safran \& Muran, 1998).

Psychodynamic theory is useful to understand how the psychotherapist in the present case thought about her interventions and conceptualizations. However, psychodynamic theory does not constitute our main analytic and interpretive framework, thus we do not specifically discuss dynamic psychotherapy in the results. Instead, we focus on the psychotherapeutic relationship as one of the most important common therapeutic factors (Lambert, 2013). Our interest lies in the working alliance aspects which support the cooperation regardless of theoretical orientation of the therapist. Thus, we did not measure the therapist's adherence to psychodynamic therapy.

\section{Measures}

In our measure selection, we preferred tools that had available psychometric verification on the Czech population and had good psychometric properties. Our aim was to select tools capturing psychotherapy outcome, working alliance, and the process of change.

\section{Personal Health Questionnaire-9}

Personal Health Questionnaire-9 (PHQ-9) is a 9-item instrument used for the assessment of depression. We used it to capture changes in depressive symptoms. Two factors were identified in the Czech version: the Somatic and the Emotional-cognitive factor (Daňsová, Masopustová, Hanáčková, Kicková, \& Korábová, 2016). An excellent internal consistency $(\alpha=.81)$ was reported in the Czech sample. Manea, Gilbody, and McMillan (2012) recommended the use of the score range of 8-11 as a cutoff for the screening of a major depressive episode. 


\section{Clinical Outcome in Routine Evaluation-Short Form}

Clinical Outcome in Routine Evaluation-Short Form (CORE-SF) is an 18-item version of CORE-OM, a general symptom measure covering four domains: wellbeing, social functioning, problems/symptoms, and risk to self/others. We used this measure to capture the symptomatic change throughout the psychotherapy. Psychometric evaluation of the Czech version was used in the CC and Reliable Change Index calculation (Juhová et al., 2018).

\section{Working Alliance Inventory-Short, Revised Form}

Working Alliance Inventory-Short, Revised Form (WAI-SR) is a short (12-item) version of an inventory measuring working alliance. The inventory was designed to measure three factors of the working alliance: Goal, Task, and Bond. WAI-SR shows moderate to high correlations with other alliance measures (Munder, Wilmers, Leonhart, Linster, \& Barth, 2009). Czech translation was developed for the study purpose. First, an initial item translation was made in a group of researchers, the item wording was then refined using cognitive interview, translated back to English by an independent translator, and then reviewed by the authors of the original version. Psychometric evaluation of the Czech translation is not yet available.

\section{Session Rating Scale}

This brief measure of the quality of the working alliance consists of only four graphical-scale items (Bond, Tasks, Goals, and overall alliance quality). Although it exhibits a ceiling effect, the scale is sensitive for use in tracking alliance ruptures and has a moderate test-retest reliability $(r=.64)$, an excellent internal consistency $(\alpha=.85-.95)$, and a moderate correlation with the short form of Working Alliance Inventory ( $r=.31-.46)$ (Janse, Boezen-Hilberdink, van Dijk, Verbraak, \& Hutschemaekers, 2014). We used Session Rating Scale (SRS) because it has good psychometric qualities and its simplicity allows more frequent administration.

\section{Interpersonal Process Recall}

The Interpersonal Process Recall (IPR) is a semistructured interview method used to explore the experiencing and the thoughts of participants during moments captured on a video- or audio-recording (Elliott, 1986; Timulák, 2010). In the present study, IPRs were used to capture the ways in which the client and the psychotherapist experienced three selected sessions. Following a 20minute break after the session's conclusion, a recording of the whole session was played back to the participant, who stopped the recording when she identified a moment in the session that was important for her. She was then asked by the researcher about her experiencing, thoughts, and bodily sensations in that moment. The IPRs were video-recorded and transcribed verbatim.

\section{Helpful Aspects of Therapy form}

The Helpful Aspects of Therapy form (HAT) is an instrument that asks clients to describe in writing the most important events that occurred during psychotherapy sessions (Elliott, 1993; Llewelyn, 1988) These clients are asked to elaborate the factors that made the events important and what they took from them, and to rate how helpful or hindering the events were. In addition, a version focusing on important events that occurred between sessions (HAT-b) was also used.

\section{Client Change Interview}

The Client Change Interview (CCI), a semi-structured interview developed by Elliott and Rodgers (2008) for qualitative and quantitative assessment of psychotherapeutic change from the perspective of clients (Elliott, 2002). Its questions focus on several areas: changes for the better or worse perceived by clients since the beginning of their therapy; the evaluation of these changes as more or less surprising, as more or less likely to have happened even without psychotherapy, and as more or less important; perceived extra- and intra-therapeutic causes of changes; client resources and limitations that affect the changes; and perceived helpful and hindering aspects of psychotherapy. Furthermore, the CCI-t for psychotherapists was created. This version focuses on changes perceived by psychotherapists and covers the same areas as the original CCI.

\section{Case formulation}

A semi-structured case formulation was completed by the psychotherapist after session 5. The case formulation served to summarize the psychotherapist's thinking about the case. Four questions were answered in writing: i) What information do I consider important? ii) What are my personal associations and experiences regarding the case? iii) How do I think about the case, how do I understand what is going on here? iv) What do I focus on when working with the client and why?

\section{Procedure}

\section{Recruitment}

The psychotherapist responded to an e-mail disseminated among local Czech practitioners. Ela responded to an advertisement offering 20 psychotherapy sessions free of charge. The ad contained a list of depressive symptoms as a self-referral guide; it was compiled using DSM-IV and ICD-10 items. Those who replied to the advertisement underwent a screening interview to assess the severity of their symptoms, including the administration of PHQ-9 measure. The PHQ-9 results (14 points, the scores 10-14 are the indication of a moderate symptom severity; Kroenke \& Spitzer, 2002) and the anamnesis indicated a moderate depressive episode according to the ICD-10 manual (WHO, 1992). 
Informed consent in writing was obtained from both participants. The project was approved by the Research Ethics Committee of Masaryk University (no. EKV2016-005).

\section{Data creation}

Before the start of the psychotherapy, descriptive and anamnestic information about the client was collected. The psychotherapy took place in a university consultation room and consisted of 18 50-minute sessions. All sessions were video-recorded. Until session 14, the dyad met weekly. The psychotherapist was pregnant and gave birth after session 14; the ensuing break was 14 weeks long. After the break, weekly sessions resumed.

All measures and interviews were administered by the study authors. The CORE-SF and the HAT-b were administered to the client before every session. The PHQ-9 was administered prior to the therapy start to assess depression severity, before the first session, and two weeks after the last session. The SRS and the HAT were completed by the client after every session; the HAT-t was administered to the psychotherapist after every session. The WAI was completed by both the client and the psychotherapist after sessions 3, 9, 13, and 18. After sessions 3, 9, and 13, IPR interviews were conducted separately with both participants. An IPR on session 18 was planned as well. However, it did not take place, because the client felt it would be too difficult for her and withdrew. After psychotherapy concluded, the client remained in touch with the research staff, but not with the therapist. CCI was administered with both participants 14 days after the psychotherapy concluded.

\section{Analysis}

The client's progress was evaluated quantitatively using the concepts of clinically significant and statistically reliable change (Jacobson \& Truax, 1991). The Reliable Change Index calculation was based on the internal consistency of the measures (Schauenburg \& Strack, 1999).

All the sessions and the interviews were transcribed verbatim and analyzed qualitatively by a team of five researchers using thematic analysis (Braun \& Clarke, 2006). Four researchers (PD, MC, LU and RH) analyzed the IPR interviews and developed categories describing the important moments perceived by the psychotherapist and the client. Each description included the topic the dyad talked about, their reasons for selecting of the moment as important, the description of interaction, including emotional and bodily experiences of participants, and the results of the interaction. Another two researchers (PD, JR) analyzed the session transcripts and developed categories that captured three working alliance factors (goals, tasks, bond). The HAT forms were used to capture the participants' perspectives after each session in this analysis. After these two qualitative analyses were finished, $\mathrm{MC}$ checked the fit between the final categories and the data. The first and the second authors, who were familiar with the whole dataset, then held discussions in which they summarized the results of the qualitative analyses into a final summary representing the three working alliance domains.

\section{Results}

\section{Introductory information}

\section{Presenting complaints}

At the first psychotherapy session, Ela presented her lack of interest in previously enjoyable activities, avoidance of social contact, and feeling of exhaustion after any social contact. She also said that she had felt self-conscious about her weight and physical appearance since adolescence. She said that she tended to compare herself with others excessively and to be dependent on others' opinions. She also expressed an absence of any interest in life.

\section{Chronological summary of sessions}

At sessions 1 through 6, the dyad mainly discussed Ela's relationship with her parents and her agency within this relationship, her lack of romantic relationships, her dissatisfaction with her own body, her perfectionism, and her tendency to hide her true feelings. She stressed that the main reason for her depressive symptoms was her physical appearance, which she blamed for her lack of romantic relationships.

During sessions 7 through 14, the dyad focused heavily on the new romantic relationship Ela had formed. They explored her experiencing in the relationship and discussed various day-to-day situations she encountered with her boyfriend. On a more abstract level, the dyad focused on Ela's agency and behavior in diverse relationships, including agency in relationships with her friends and parents, and specifically with her father. The psychotherapist gave birth several days after session 14. After a 14-week break, the psychotherapy continued.

At Sessions 15 through 18, the dyad explored Ela's current life situation. When asked by the psychotherapist, she said that her wellbeing had a score 9 out of 10 and noted multiple changes in her life that had occurred since the beginning of the psychotherapy. Yet she was not sure that the changes would be maintained even if she broke up with her boyfriend, and she had concerns about her future job perspective; hence she wanted to continue with sessions.

Session 18 was emotionally very laden for Ela, and it was the last session (out of the planned 20). The dyad discussed Ela's plans for the future and focused on her tendency to comply with her parents' demands - to do what one is supposed to do. A week after this session, Ela told the researchers that she did not want to continue with the therapy, stressing her need to focus on finishing her studies and her unwillingness to delve into the analysis of difficult themes. Hence, the client remained in contact with 
the research staff, but not with the therapist, although researchers offered the client to contact the therapist via email or meet her personally. However, the psychotherapist did not consider the psychotherapy as having been completed.

Events such as long break in therapy and limited number of sessions may impact clients, so it is useful to describe how the dyad negotiated these events. At the session 7, they discussed the limited number of 20 sessions and the therapist's pregnancy. The therapist offered several solutions, like referrals to her colleagues. However, the dyad did not discuss any emotional or relational meaning of this situation. The childbirth was an unexpected event, as the therapist delivered prematurely. When the therapy started again, at the session 15, they briefly discussed the 14-week break and proceeded to evaluate Ela's current life situation, without putting any emphasis on the break. Neither participant also addressed the break as a problem in subsequent interviews, thus we assume that the event did not negatively impact the client and by itself, the break did not lead to the client's dropout.

\section{Outcome}

\section{Outcome measures}

Table 1 summarizes the outcome as measured via CORE-OM and PHQ-9. On both measures, Ela started in the clinical range and reached the criteria for a recovery by the end of the therapy. Figure 1 depicts the CORE-SF scores as measured on a session-by-session basis. The graph shows a steady progress with several mild setbacks (with none of them meeting the criteria for a statistically reliable deterioration).

\section{The client perspective}

Within the retrospective CCI interview, Ela formulated several positive changes. These changes are listed in Table 2 along with Ela's evaluation of their expectedness, personal importance, and subjectively assessed probability of occurrence without psychotherapy. Overall, she evaluated her state as: much better (...), like 80 or 90 percent better than at the beginning of the psychotherapy.

Table 1. Summary of quantitative outcome data.

\begin{tabular}{llllllll}
\hline Variable & Clinical cutoff & RCI & Pre-Tx & Post-Tx & Min & Max & Classification \\
\hline CORE-SF & 1.349 & 0.45 & 2.088 & 0.611 & 0 & 4 & Recovered \\
\hline PHQ-9 & 8 & 6 & 14 & 2 & 0 & 27 & Recovered \\
\hline
\end{tabular}

Outcome scores were classified according to Jacobson and Truax (1991) criteria of statistically reliable and clinically significant change. RCI, Reliable Change Index; CORE-SF, clinical outcome in routine evaluation-short form; PHQ-9, personal health questionnaire-9.

\section{Table 2. Summary of client- and therapist-identified changes.}

\begin{tabular}{|c|c|c|c|}
\hline Change description & Expectedness & $\begin{array}{l}\text { Probability w/o } \\
\text { psychotherapy }\end{array}$ & Personal importance \\
\hline \multicolumn{4}{|l|}{ Changes identified by the client } \\
\hline Much happier, noticed by herself and others around her & Very much expected it & $\begin{array}{l}\text { Very unlikely without } \\
\text { psychotherapy }\end{array}$ & Extremely important \\
\hline Less stressed overall & Somewhat surprised by it & $\begin{array}{l}\text { Somewhat unlikely without } \\
\text { psychotherapy }\end{array}$ & Extremely important \\
\hline $\begin{array}{l}\text { Less occupied by everyday problems and } \\
\text { their peculiarities }\end{array}$ & Somewhat expected it & Neither likely nor unlikely & Moderately important \\
\hline $\begin{array}{l}\text { Not so occupied with opinions of others, others } \\
\text { cannot throw her off balance easily }\end{array}$ & Somewhat surprised by it & $\begin{array}{l}\text { Somewhat unlikely without } \\
\text { psychotherapy }\end{array}$ & Slightly important \\
\hline $\begin{array}{l}\text { Less troubled by normal activities, primarily } \\
\text { associated with food (eating out) }\end{array}$ & $\begin{array}{l}\text { Neither expected nor } \\
\text { surprised by the change }\end{array}$ & $\begin{array}{l}\text { Somewhat likely without } \\
\text { psychotherapy }\end{array}$ & Moderately important \\
\hline \multicolumn{4}{|l|}{ Changes identified by the therapist } \\
\hline $\begin{array}{l}\text { Changes in appearance: The client started to get } \\
\text { dressed in a more attractive and cheerful way }\end{array}$ & Somewhat surprised by it & $\begin{array}{l}\text { Somewhat unlikely without } \\
\text { therapy }\end{array}$ & Slightly important \\
\hline Satisfaction with herself, self-confidence, and optimism & Somewhat expected it & $\begin{array}{l}\text { Somewhat likely without } \\
\text { therapy }\end{array}$ & Extremely important \\
\hline $\begin{array}{l}\text { Being more open and courageous in her relationships } \\
\text { in general, and especially with her parents }\end{array}$ & Very much expected it & $\begin{array}{l}\text { Very unlikely without } \\
\text { therapy }\end{array}$ & Very important \\
\hline Establishing a new romantic relationship & Somewhat surprised by it & Very likely without therapy & Extremely important \\
\hline
\end{tabular}


Furthermore, she felt that the most important issues she had wanted to change had improved.

There were another two changes that Ela mentioned without scoring their importance, expectedness, or probability of occurrence without psychotherapy. First, she developed a new romantic relationship during the psychotherapy, which, in her opinion, was one of the sources of her increased happiness and self-confidence. However, she did not explicitly attribute the formation of the relationship to the psychotherapy. Second, Ela said she had attained an insight into her close relationships, especially with her family. Although she reported it might influence her positively in the future, at the time of the interview, she evaluated this as a negative change. She was uncomfortable with the realization of how much her life was determined by her parents' wishes. At the time of the interview, she felt unprepared for changes in this area and felt misunderstood in this regard by the psychotherapist.

\section{The psychotherapist's perspective}

The psychotherapist identified four changes, described in the lower part of Table 2. One of the changes was seen as somewhat problematic by the psychotherapist - she described Ela as moving from a submissive position to an over-confident, or even arrogant one. The psychotherapist assessed this change as premature, unintegrated, and prone to a relapse. Furthermore, according to the psychotherapist, additional work would be needed for the behavioral changes to become more socially convenient.

The psychotherapist expressed the opinion that the new romantic relationship would probably have started even without therapy. Nevertheless, she also reflected that Ela's becoming more open and courageous in her relationships could have played a positive role in this.

\section{Summary of the outcome data}

We can conclude that the psychotherapy was successful from the perspective of symptomatic change, since the client changed in all of the administered measures (PHQ-
9, CORE-SF) both clinically and statistically, reaching the criteria for recovery. From the qualitative perspective of CCI, many positive changes were reported and attributed to the psychotherapy by both the client and the psychotherapist.

Yet at the same time, several signs suggest that the therapy was terminated prematurely (Swift \& Greenberg, 2014). First, it was terminated by the client unilaterally, without discussion with the psychotherapist. Second, several changes were evaluated as unwanted by the client or assessed as unfinished and unstable by the psychotherapist. The following question thus arises: What contributed to the significant outcome and, at the same time, what contributed to the premature termination? We will address this question by inspecting the process data.

\section{The working alliance}

The data provided by the SRS (Figure 2) shows that the alliance quality, as perceived by the client, increased gradually until session 5 and then remained primarily stable, with two marked drops at sessions 13 and 18 (Figure 2). The WAI data shows a stable alliance for both the client and the psychotherapist. A closer examination of the data shows that the client scored the goal factor somewhat lower than the other factors (Figure 3).

Meanwhile an examination of the recordings of sessions 13 and 18 did not reveal any significant deviations from the usual course of work. At first, the way the dyad worked could have been conducive towards a good outcome, but as the psychotherapy progressed, it could have proven insufficient for Ela's changing needs. To explore this hypothesis further, we provide a qualitative description of the three working alliance factors: goals, tasks, and bond.

\section{Goals}

The psychotherapist and the client worked together on various topics, including the client's attitude towards

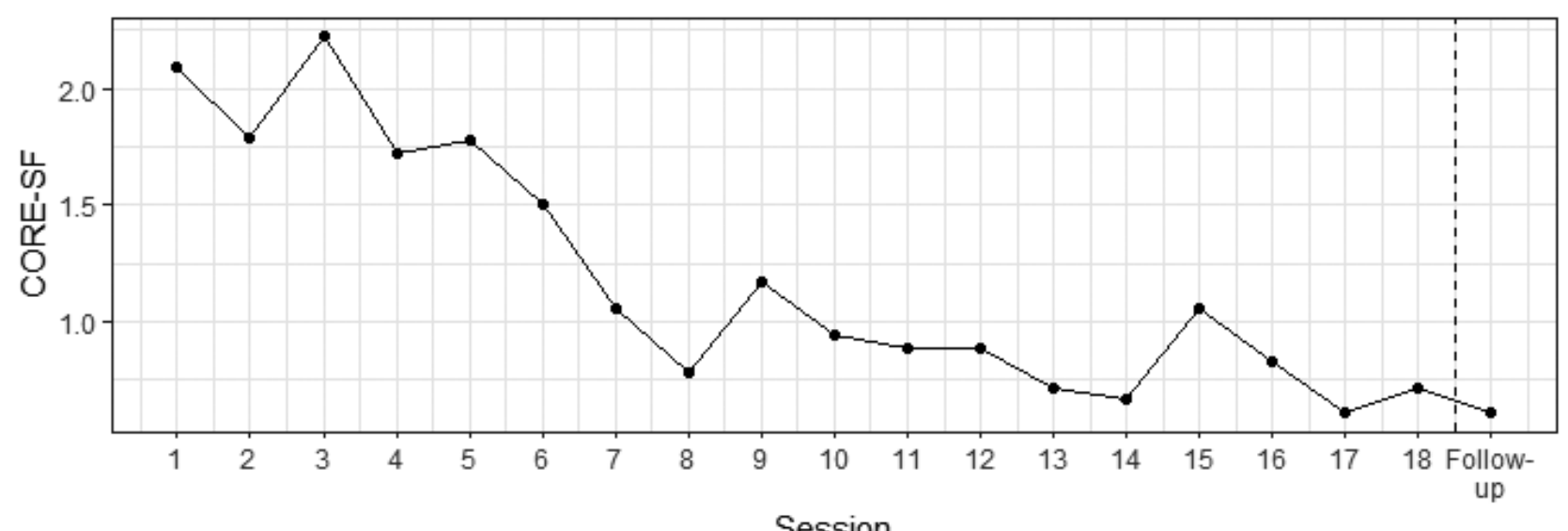

Figure 1. Clinical outcome in routine evaluation-short form (CORE-SF) scores. 
herself and her body, her self-confidence, her relationships with her boyfriend and other friends, and her social contacts in general. The psychotherapist occasionally stressed that the psychotherapy was about any topics Ela brought in, but the dyad did not discuss psychotherapy goals explicitly; therefore, the goal-setting agenda remained implicit.

One of the psychotherapist's aims was to remain at the level of Ela's experiencing and to help her understand her emotions and needs. However, these goals were not mentioned at the sessions explicitly. In the last session, the psychotherapist pointed Ela towards her agency in her relationship with family and in her work, without an explicit agreement on the usefulness of this topic. Ela experienced this as unhelpful and emotionally difficult. This was apparent in the CCI, where she stated that she needed to focus on finishing school and did not want to delve deeper into the analysis of the influences her parents had on her. She stated in the CCI that:

She thought it can be done and I just know that it cannot. She's got this sense that I could do something about it now. But now, right before finishing my diploma thesis and final exams, I really do not need to change anything or deal with it.

The lack of explicit discussion of goals could be linked to later issues with the identification of useful tasks when the client's life circumstances changed. This observation is in accordance with the fact that the goal consensus received the lowest ratings compared to the other dimensions on all four WAI measurement points (Figure 3). Even if it is not always necessary to discuss goals explicitly, this could help in finding a response to the client's emerging needs. Moreover, the fact that the psychotherapy was short term, with an unexpected break after the session 14, highlights the need to explicitly discuss goals in a more detailed way.

\section{Tasks}

The Task dimension of the working alliance refers to interventions and modes of interaction intended to achieve psychotherapy goals. Based on a review of the session transcripts, as well as data from CCIs, IPRs, and HATs, we identified several features typical for this psychotherapy process: i) the use of interpretations, suggestions, and advice; ii) friendly sharing and encouragement from the psychotherapist; iii) addressing emotions; and iv) the support of Ela's agency. While these features were effective at some times, they seemed to be hindering at others, providing an ambivalent picture of the psychotherapy process.

\section{Interpretations, suggestions, and advice}

Interpretations and suggestions were dominant interventions throughout the therapy. A common pattern was identified: the dyad explored Ela's problem, then the psychotherapist took more talking space and offered interpretations, insights, and suggestions. These interventions worked when they pleased the client, when they put her in a better position than she assumed for herself, or when she considered the suggestions to be useful in her daily life. This type of intervention occurred for example when Ela described that she was planning to go for a walk with a man who was romantically interested in her, although she did not want to go (numbers in brackets indicate the delay in speaking in seconds):

$\mathrm{T}$ : But you are on your own now, and you agreed to go even if you would rather not.

C: $\mathrm{Hm}$.

T: So really you are being a bit masochistic.

C: [laughs] I know; for a long time now I've been saying that I have to learn to say no, and sometimes I can do that.

$\mathrm{T}$ : There are middle grounds to take or compromises to make. How do you imagine this walk will go?

C: [laughs] I prefer not to imagine that. It's gonna be (.) it's gonna be catastrophic, I can see it (1) hm. (5) I don't know... (5) I have to tell him clearly that we are just going to be friends.

In the HAT, Ela described this conversation as a helpful event, stating: I should be more aware of my feelings and follow them, I should not do stuff I don't want to do. (HAT, session 7). She later went on to follow this insight, cancelling the walk.

Generally, Ela appreciated this type of intervention:

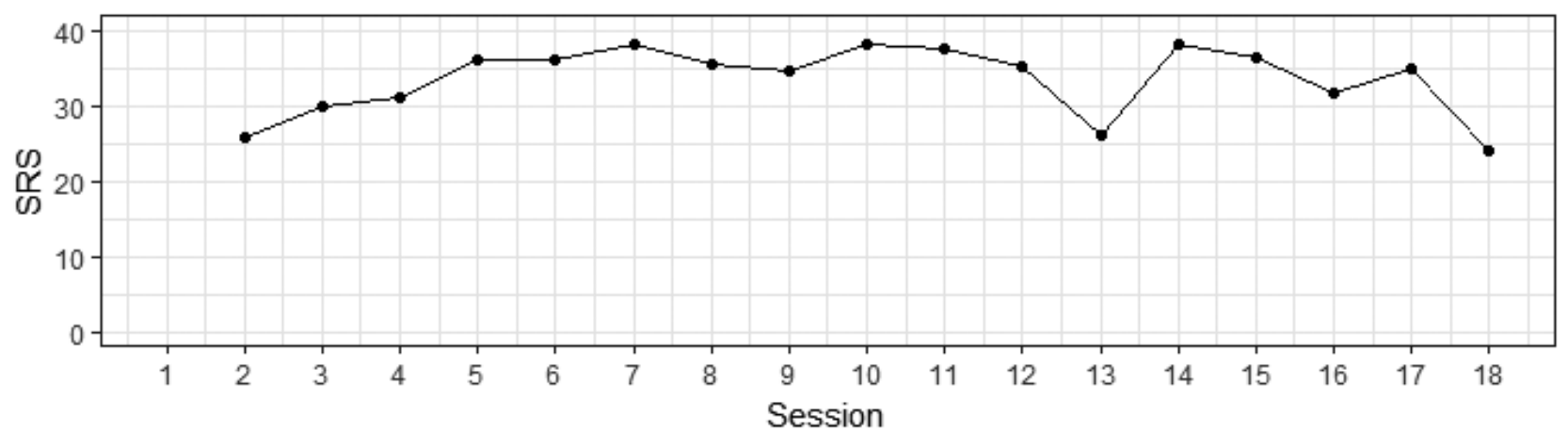

Figure 2. Session rating scale (SRS) scores. 
When there was a problem we talked about it (.) with conclusions about what was wrong or what could be done better (CCI). She valued the psychotherapist's insights and different points of view and felt free to discard them in case she did not find them useful.

However, interpretations, suggestions, and advice did not work well for one specific topic-Ela's relationship with her father. The psychotherapist repeatedly suggested that Ela should be more assertive towards her father. Ela stated in the CCI that the psychotherapist could not imagine the relationship's dynamics well enough. Therefore, the psychotherapist could not help her in the way she needed. Session 12 saw a culmination of this interaction:

T: I'm wondering, what if you told him: 'I've got this feeling that maybe you worry about me, and that's why you talk like that... and I'm glad that you worry about me. 'I'm wondering, if you say something like that - put into words something that he can't say, that he may be experiencing - maybe he wouldn't refuse it entirely.

C: Mhm. (3) [quiet voice] Maybe not. (10)

T: So how did you spend Tuesday? (3)

In the HAT form, Ela described this moment as hindering: I realized that this is too difficult for me, and I would rather let it be. (HAT, session 12) When the relationship with Ela's father was discussed, she kept opposing the psychotherapist, remained passive, or stopped explaining her view and flatly affirmed the psychotherapist. This pattern became more frequent as the therapy progressed. We assume that these repeated reactions were a sign that the intervention exhausted its potential. Invalidation of an intervention by the client may signalize that the dyad had reached the upper limit of the therapeutic zone of proximal development and may have needed a different approach (Stiles, Caro Gabalda, \& Ribeiro, 2016).

\section{Friendly sharing and encouragement}

Conversations on various topics provided Ela with a space to explore her experiences with the psychotherapist,

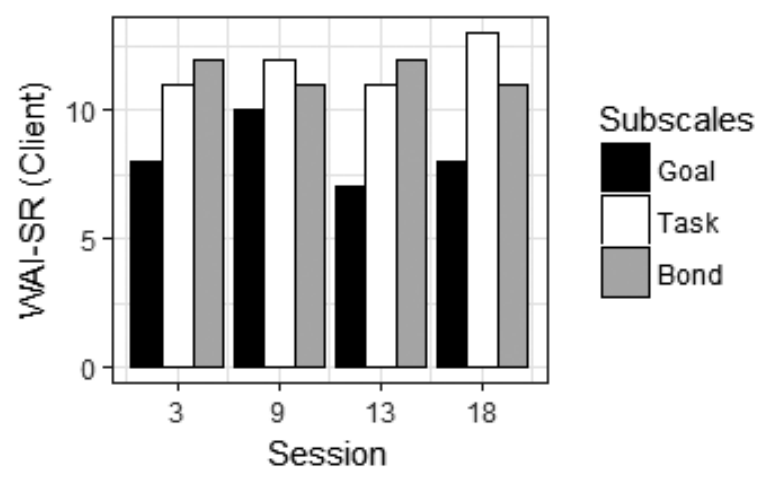

Figure 3. Working alliance inventory - short, revised form (WAI-SR) scores. who encouraged and reassured her. For example, this type of task helped Ela to explore her attitudes towards her studies and her relationship with her body. In the context of body image, they talked about shopping for clothes, which developed into a moment that was identified by Ela as helpful in the first IPR:

$\mathrm{C}$ : I also like colors. But then it is problematic to get something I like in my size.

T: What is your size, Ela?

C: 44

T: You think this is some mammoth size? You said that as if there were no other people like that in the world. But that is just a normal, average size.

During this IPR, Ela also stated that this was the most important moment of the whole session, saying: At this moment I realized that others may perceive my size really differently. She was surprised and felt happy. However, the psychotherapist saw encouraging a client as something she was not used to. She described this in the second IPR, after the 9th session, as follows:

I get this tendency, more urgent than with other clients, to support her; maybe it isn't the best thing to do to acknowledge her, to express my opinion. And I'm not used to doing that, but with her, I'm in this role, this maternal role, and I don't like it, but I sometimes feel that she needs to be appreciated. To be given something.

Although the therapist did not like to give explicit support to the client, she was responsive to Ela's needs and varied from her usual working style in favor of the client. However, as the psychotherapy progressed, this type of intervention was listed as important by the client less often in the HATs and IPRs. She seemed to now be able to provide the support she needed for herself. She reported that her boyfriend fulfilled this need as well.

\section{Addressing emotions}

The dyad most often remained at the cognitive or behavioral level, without an explicit focus on emotions. In the case formulation, the psychotherapist stated that her goal was to work more on the here and now level so as to help Ela understand her own experiencing. Yet it seemed difficult for the dyad to find a way of working with emotions. The psychotherapist was aware of this, as she reflected during the IPR after session 13:

It is hard for her to talk about her feelings, and I was wondering what to do (.) whether she was going to talk about her feelings or not. It wasn't coming, so I began to feel annoyed, as I was struggling to find a way to work with this.

When the dyad did try to work with feelings, they would not maintain this focus for a long time. For example, after the psychotherapist asked questions in which she aimed at Ela's experiencing, the dialogue quickly switched to questions on a cognitive level, as observed in session 13: 
$\mathrm{T}$ : (5) It is probably pleasant to experience that he does not want to leave you. Tell me, how do you feel when you say goodbye to each other and you drive home?

C: Well, I do not feel like going away and I would rather stay with him. (11) I like that he texts me immediately after he arrives home. I like it, and I text him as well. T: (11) So, what do you two have in common?

In this moment, the psychotherapist explored the feelings Ela had in a situation, but after a short remark by the client, she asked another question focused on the things Ela and her boyfriend had in common, abandoning the theme of feelings. The difficulty in addressing emotions manifested on the here and now level as well. Ela experienced strong feelings in relation to questions the psychotherapist asked; however, these feelings were not addressed verbally. Furthermore, working on a cognitive level was not fruitful here; Ela mentioned the psychotherapists' factual questions during the IPR as digging and she felt she did not have the needed answers.

It is unclear whether Ela herself wanted to work with her emotions and considered such work to be useful, because she did not express her wishes in this matter, nor did she mention this focus as important in the IPRs or the CCI. However, a change in her focus towards facets different from the cognitive level may be reflected in the reconsideration she gave to her tendency to analyze and worry too much and being fed up with that (Session 10).

\section{Supporting the client's agency}

The cognitive, encouraging approach that contributed to the psychotherapy outcome was linked to the psychotherapist's focus on the development of Ela's agency. She repeatedly suggested to Ela to be more assertive, both via direct prompts to take a more active stance in various life events, and on a subtler level, where she helped Ela to defuse her fears.

As the psychotherapy progressed, Ela's agency strengthened - as she reflected in the CCI. For example, she stated that she was assertively reacting to her father's behavior. However, the relationship with Ela's parents and the way that she thought about her future life were a source of conflict in the psychotherapy, because she had the perception that her agency had certain limits. The psychotherapist suggested additional assertive behaviors towards Ela's father, while Ela stated that further assertiveness was unrealistic.

Although the psychotherapist focused on supporting the client's agency in her life, the dyad struggled to find a way of using her agency within the psychotherapeutic process itself. This was evident at session 4, when the psychotherapist tried to invite Ela to take a more active position in directing the therapeutic process.

T: Do you have any ideas on what's meaningful for you to talk about?

\section{C: I don't know what I should talk about (5). I don't know exactly, but sometimes I feel like I'm talking off-topic.}

T: In any case, if you have the feeling that we're focusing on something you don't consider useful, this is your hour really, and I can't see into your head, so try to give me some feedback, and don't be afraid to say, 'I want to leave this topic.' For example, what did you take from the last session?

(2) What kinds of feelings?

C: (2) It was alright last time. I felt composed. I don't know how to describe it.

T: Today, you seem a bit wary, insecure, maybe tired.

$\mathrm{C}: \mathrm{Hm}$.

T: Try to tell me how you're doing today.

The psychotherapist offered Ela a chance to take the lead and direct the sessions more. However, in the end, she did not explicitly ask Ela about the course she would like to take in the psychotherapy. Instead, the psychotherapist immediately asked a question about the previous session. This question could have been interpreted by Ela as a space to think about the things she liked or disliked about the last session and to outline the course that she would like for the following sessions to take. However, she struggled to find words for her needs and experiences. The psychotherapist reacted with an active position in shaping the conversation and changed the subject to Ela's current status. Although the psychotherapist reflected that this was not typical for her style of work, she was leading most of the time. However, Ela never complained. In fact, she may have expected the psychotherapist to take the lead. This was shown in a discussion about silences that occurred:

Sometimes there are passages with a very long silence. And I do not have anything to add...I think that by being silent nothing can be solved. I would prefer for the psychotherapist to ask me questions; I find that more effective.

\section{Therapeutic bond}

Bond refers to the feelings emerging between the client and the psychotherapist - the level of trust, acceptance, and confidence. Ela described the psychotherapist as a professional whose job was to listen to what she brought into sessions and who offered different points of view. As advantages of this view, Ela named that the psychotherapist was someone whom Ela could tell about experiences in her life that she would not or could not tell to someone closer to her and who would be unbiased when providing feedback. This helped Ela to speak without restraint and choose whether or not she would use what the psychotherapist suggested. In the CCI, Ela stated:

When I talk about something with my mom or my friend, I feel that they're not very interested. Or I feel I'm bothering them. The psychotherapist is 
there just for this; it's her job, and I can approach her with my problems without fear.

This concept of the psychotherapist who offers unbiased advice and whose needs do not need to be taken care of in the interpersonal relationship was also one of the reasons why she pointed out the psychotherapist's support as useful. The psychotherapist was not forced to comfort Ela due to their being close personally, and therefore Ela deemed the encouragements to be more truthful.

The low level of closeness Ela felt in the psychotherapeutic relationship could also have functioned as a hindering factor. Several times, Ela described the psychotherapist as someone who knows relatively little about her and who is not close enough. For example, at Session 9, Ela was surprised by the psychotherapist's questions about her feelings and her body experiencing in a moment of physical intimacy with her boyfriend.

That question was very unpleasant, because...I

don't know the psychotherapist in a way that would make me enjoy talking to her about such things. I would rather get up and walk away in that moment or...just tell her I don't want to talk about this!

The low level of closeness present in the psychotherapeutic relationship may also have contributed to difficulties in attempts to discuss more emotionally laden topics, because Ela did not perceive the psychotherapist as someone close enough to talk about intimate feelings. Yet when the quantitative and qualitative data were examined, surprisingly, there was no evidence of dissatisfaction with the overall bond quality. However, Ela's tendency towards pleasing others may have biased the results. On the other hand, this may be evidence that the therapeutic relationship worked well at the cognitive level and that Ela perceived that as satisfactory.

From the psychotherapist's perspective, the emotional bond between the dyad could be characterized as a process of alternating between approaching and moving away from the client. The psychotherapist felt closeness in the moments when Ela kept focused on her own experiencing. She felt more distance from Ela when she did not understand what Ela was talking about and when she viewed Ela's opinions as out of place. Furthermore, she tended to get annoyed or bored when Ela repeated certain of her beliefs, especially the belief about her physical appearance causing most of her problems. The psychotherapist summed this up during the second IPR (session 9): She drives me crazy with her conviction that her appearance causes all of her problems. I had to control myself so as not to react personally.

The psychotherapist stated that she had different personality traits than Ela, and hence it was difficult for her to accept some of Ela's tendencies and not to feel antipathy. She was aware of the demands she had on the client and accommodated her own impatience by reminding herself not to hurry the process. She acknowledged that it was difficult for Ela to be close to other people, and she was wary of frightening her; therefore, she sometimes resorted to a level of working that she herself considered shallower and less engaged.

\section{Discussion}

In this study, we have presented the case of a woman with moderate depressive symptoms, who improved on all outcome measures in psychotherapy. The client expressed that - in addition to her symptomatic improvement - she had experienced improvements to her quality of life and social functioning. However, despite these improvements, the client decided to drop out of the psychotherapy. She did not express to the psychotherapist any dissatisfaction with the outcome or with the psychotherapy in general. In the paragraphs below, we will discuss the ambiguity present in this case.

The concept of responsiveness and the aspects of therapeutic relationship that we focused on in the data analysis will help us explain this ambiguity. The present case shows the importance of two levels of responsiveness outlined by Edwards (2010). At the first level, psychotherapists adapt their interventions to clients' momentary emotional states, needs, goals, and the session flow. At the second level, they are responsive to the changes in clients' needs as the therapy progresses and they adapt their working style to these changes. In the following text, we first discuss how, in the present case, the therapist adapted her style of working to the client's initial needs and how this contributed to the symptomatic improvement. Then, we discuss how the changes the client experienced may have required new working alliance configuration, and how this could be linked to the client dropout.

\section{Psychotherapist responsiveness to the client's initial needs}

In the present case, the client valued moments when the psychotherapist showed positive regard, offered friendly sharing, and placed the client into a better perspective than the client had assumed for herself. Barnicot, Wampold, and Priebe (2014) showed that in the treatment of depressive symptoms, psychotherapists' genuineness (expressing true feelings and attitudes) and positive regard (caring for clients and showing warmth) are linked to better outcomes. These aspects are also considered important in the early stages of short term therapy (Safran \& Muran, 1998) and they contributed to the symptomatic improvement also in the present case. However, providing both positive regard and genuineness at the same time was difficult for this therapist. Hence, she had to choose which aspects to support throughout the psychotherapy - and this was reflected in the working alliance configuration.

The IPR interviews showed that although the psychotherapist expressed positive regard and empathy, she 
was not content to reassure the client too much, because it differed from how she was supposed to work in her own view of dynamic psychotherapy, and. As a result, even though she provided positive regard, her genuineness was diminished. This can be perceived as a helpful choice at the moment. Hatcher (2010) has pointed out that the working alliance is a way of looking at the therapeutic relationship through the lens of effective goal-directed work. In this sense, the therapist deliberately chose to support an effective aspect of the working alliance, even though this led to limitations in the usage of another important part of the therapeutic relationship. This choice further contributed to the working alliance's configuration, because the limited genuineness may also have resulted in the emotional distance between the participants and their struggle to address emotionally laden topics.

The interrelations among different relationship factors outlined for the present case show how the most important relationship factors may contradict each other, forcing the psychotherapist to responsively choose which factor to support with a specific client or at a particular session. In other words, the choices the psychotherapist had to make underscore the need for moment-to-moment responsiveness and attunement to the client (Swift, Tompkins, \& Parkin, 2017). In the present case, it was the psychotherapist's adherence to the principles of the psychodynamic orientation that limited her responsiveness, as they did not enable her to utilize certain resources. The integration of both external (i.e., psychotherapy theory) and internal (i.e., clinical experience) sources of understanding is associated with the work of expert psychotherapists (Řiháček \& Danelová, 2016; Ronnestad \& Skovholt, 2013), and it represents a challenge that must be dealt with in daily practice. The present case illustrates some of the implications of this challenge.

In addition to the choice the therapist made regarding the use of positive regard, another responsive reaction by the psychotherapist was also identified here in the practical and encouraging approach she employed at the beginning of the psychotherapy, when the client had rather intense depressive symptoms. This problem-solving approach consisted of interpretations, suggestions, and advice, which the client perceived as useful. It was likely the relative emotional distance between the client and the therapist that helped to make these tasks useful, because it enabled the client to treat the therapist as a neutral actor, and therefore a valuable provider of information and recommendations. This choice of working style by the psychotherapist most likely led to a useful working alliance configuration, because for clients with depressive symptoms, problem-solving interventions may be more effective than cognitive-behavioral and interpersonal therapies (Cuijpers, Van Straten, Warmerdam, \& Smits, 2008). Furthermore, it has been shown that clients with depression prioritize functional outcomes (i.e. a return to functioning at work, school, and home) in treatment (Zimmerman et al., 2006).

Although the problem-solving working alliance con- figuration was useful during the initial phases of psychotherapy, it seems that it exhausted its potential after the client achieved a functional outcome. The relative emotional distance between the client and the therapist and the degree of the psychotherapist's ability to renegotiate the alliance when circumstances changed may have prompted the ruptures to the working alliance and the later dropout. This shows the importance of the psychotherapist's metacompetency responsiveness: As the client experienced changes in her life, a different approach and relationship configuration may have been needed.

\section{Psychotherapist responsiveness to changes occurring during psychotherapy}

As the client's life situation changed and the therapy progressed into a different phase, she may have been ready for different tasks or a different relationship configuration than those that had worked in an earlier phase (Norcross, Krebs \& Prochaska, 2011). We suggest below five different possible ways of viewing the course which the psychotherapy took.

First, we may hypothesize that the psychotherapy went well, and that nothing needed to be changed. The client herself never complained about the emotional distance in the relationship, the lack of focus on her experiences, or the lack of possibilities for directing her own psychotherapy more. In general, she was satisfied with the psychotherapy. Thus, we may assume that the therapy had fulfilled its purpose for the client and that she simply did not see any reason to continue. She perceived meanwhile that if the dyad were to begin working on the role her upbringing had on her choices in life, the impacts would be undesirable for her. She recalled this clearly: If I try to deal with this now, I know I wouldn't enjoy my current life as much as I could.

Second, we may view this case as a missed opportunity. The lack of discussion about psychotherapy goals may have reduced the dyad's ability to be responsive to new circumstances. To discuss and to define realistic psychotherapy goals is important in short term psychotherapy (Safran \& Muran, 1998). After the alleviation of the initial depressive symptoms, the therapist chose a goal that was not mutually agreed upon: the client's relationship with her father and the impacts her family had upon her choices. The client resisted work on these goals, felt pushed by the psychotherapist, and also felt that her previous efforts in solving these issues were not being acknowledged. This is in accordance with the therapeutic community's revised concept of the working alliance (Mander et al., 2015), which shows that from the client perspective, the factors Tasks, Goals, and Bond could be supplemented with the factors Therapist Interference and Patient Fears. The therapist interference factor includes the statements Today the therapist pushed me too much on certain issues and Today the therapist insufficiently acknowledged my efforts and progress. These statements, which summarize the essence of the client's complaints, 
were not captured by the WAI and SRS measures, although they were important in contributing to the client dropout. This further demonstrates that in a short term psychotherapy, it is useful to assess clients' capacity and needs in all stages of therapy to make a timely use of either interpretative, or supportive interventions (Leichsenring \& Schauenburg, 2014).

Third, the interpersonal position of the psychotherapist as an expert might be viewed as having prevented the dyad from changing how they worked together. As described by Norcross, Krebs, and Prochaska (2011), in later stages of psychotherapy, it may be necessary to choose different treatment methods and interpersonal stances. The fixed interpersonal stance could have blocked the discussion of the client's more personal topics. On the processual level, this also means that Ela's agency was not promoted in her interaction with the psychotherapist, as the psychotherapist was the one leading. While there are many ways to promote agency in a client's life (Williams \& Levitt, 2007), developing a more active position for Ela in her interaction with the therapist could have been important in this case in order to promote a more collaborative working method in later stages and thus find a way to proceed with psychotherapy or to end it more constructively. Also, this could have helped Ela to develop new ways of relating to people, and especially to her parents, with whom she experienced a lack of agency, as it is useful to change dysfunctional relationship patterns in a mutual interaction rather than for example make interpretations based upon them (Dimaggio, Fiore, Salvatore, \& Carcione, 2007).

Fourth, the dyad may be viewed as not having harnessed their working alliance so as to bring additional changes for the client because they maintained emotional distance. The client, it is true, interpreted the distance positively, positing the therapy as a cognitive learning experience. The psychotherapist, on the other hand, struggled to direct the client's focus towards her feelings. However, neither the psychotherapist nor the client explicitly addressed the emotional distance between them as the possible cause of the client's reluctance towards talking about emotions. The revised working alliance concept (Mander et al., 2015), captures these aspects in the factor called Patient Fears. It includes the statements It was too embarrassing for me today to tell the therapist about certain thoughts and feelings, Today, it was difficult for me to talk openly with the therapist about my thoughts and feelings, and During today's session, I held back my emotions. The lack of focus on emotions in the present case could have prevented the identification of core relational and emotional themes and restricted the experience of an empathic relationship bond. In return, this could have led to troubles with the articulation of shared therapeutic goals and affected the client's expectations and engagement in psychotherapy (Angus \& Kagan, 2007).

Fifth, we can view this as a situation of unresolved ruptures in the therapeutic relationship, as identified in the IPR with the client. These ruptures were neither repaired nor explicitly discussed. If not recognized and handled within the process, ruptures may hinder the process and outcome of therapy (Chen et al., 2016; Muran et al., 2009). We suggest that the psychotherapist could pay more attention to ruptures, as this could not only strengthen the psychotherapeutic relationship, but also offer a space for an exploration of interpersonal schemas, including ways of resolving differences with others (Chen et al., 2016). This could be an important learning experience for the client, and it could also have helped to prevent the dropout.

\section{Study limitations}

Video recording of sessions, the administration of questionnaires, and the presence of researchers could have influenced the psychotherapy process. When asked about the impacts of research on the therapy and herself, the client described two effects. First, writing about helpful aspects of every session helped her awareness of what was important for her in the psychotherapy. Second, she had trouble finding the right words to describe what she felt during the video recorded session moments at the IPR interviews. Thus, we may assume that, as a result of the research, the client had better awareness of the psychotherapy benefits, and that she was more aware of her difficulty to describe her own experiencing. Even though no direct impacts on the therapy process and the working alliance were reported, we may speculate that, for example, the client might have been reluctant to speak about some more intimate topics as a result of the research process. To reduce this possibility, the researchers reminded the client that all the data was anonymized and that they did not inspect the data until the end of the psychotherapy. The therapist did not report any impacts of the research on the psychotherapy process, she perceived the presence of researchers as non-intrusive for her own therapeutic work.

We chose the theoretical framing of this study, i.e., the concepts of responsiveness and the working alliance as common therapy factors, because it is relevant for various psychotherapy orientations (e.g., psychodynamic, cognitive-behavioral, experiential). This choice limited the topics we would focus on in the analysis. For instance, if we instead chose the psychodynamic theory as the main framing, we could use concepts such as transference and countertransference to explain the therapy process and outcome. This approach might yield some important insights. However, it was useful to choose a single theoretical framing to reduce the text complexity.

\section{Conclusions}

The present case study design has proven to be useful in tackling the complex and often ambiguous interaction of multiple psychotherapy process variables and the psychotherapy outcome. It has demonstrated the role of mo- 
ment-to-moment and long-term responsiveness in the psychotherapeutic alliance and shown the impact of the extent to which the alliance reflects the client's development and the influence of extratherapeutic factors. Psychotherapists should take care to be attuned towards clients and be aware that an intervention that worked for a particular client once does not need to work in the next moment or session (Swift et al., 2017). Moreover, the present study has provided insights into some dynamics leading to psychotherapy dropout in a case that, while successful, could be recorded in a large-scale study as a failure due to the psychotherapy discontinuation.

\section{References}

Ackerman, S. J., \& Hilsenroth, M. J. (2003). A review of therapist characteristics and techniques positively impacting the therapeutic alliance. Clinical Psychology Review, 23(1), 1-33.

Angus, L., \& Kagan, F. (2007). Empathic relational bonds and personal agency in psychotherapy: Implications for psychotherapy supervision, practice, and research. Psychotherapy: Theory, Research, Practice, Training, 44(4), 371-377. doi: 10.1037/0033-3204.44.4.371

Baldwin, S. A., Wampold, B. E., \& Imel, Z. E. (2007). Untangling the alliance-outcome correlation: Exploring the relative importance of therapist and patient variability in the alliance. Journal of Consulting and Clinical Psychology, 75(6), 842-852. doi: 10.1037/0022-006X.75.6.842

Barnicot, K., Wampold, B. E., \& Priebe, S. (2014). The effect of core clinician interpersonal behaviors on depression. Journal of Affective Disorders, 167, 112-117. doi: 10.1016/j.jad.2014.05.064

Bordin, E. S. (1979). The generalizability of the psychoanalytic concept of the working alliance. Psychotherapy: Theory, Research and Practice, 16(3), 252-260. doi: 10.1037/h0085885

Braun, V., \& Clarke, V. (2006). Using thematic analysis in psychology. Qualitative Research in Psychology, 3(2), 77-101. doi: 10.1191/1478088706qp063oa

Carey, T. A., \& Stiles, W. B. (2016). Some problems with randomized controlled trials and some viable alternatives. Clinical Psychology \& Psychotherapy, 23(1), 87-95. doi: 10.1002/ cpp.1942

Chen, R., Atzil-Slonim, D., Bar-Kalifa, E., Hasson-Ohayon, I., \& Refaeli, E. (2016). Therapists' recognition of alliance ruptures as a moderator of change in alliance and symptoms. Psychotherapy Research, 28(4), 560-570. doi: 10.1080/ 10503307.2016.1227104.

Crits-Christoph, P., Connolly Gibbons, M. B., \& Mukherjee, D. (2013). Psychotherapy process-outcome research. In M. J. Lambert (Ed.), Handbook of psychotherapy and behavior change (6th ed., pp. 298-340). Hoboken, NJ: John Wiley.

Cuijpers, P. (2017). Four decades of outcome research on psychotherapies for adult depression: An overview of a series of meta-analyses. Canadian Psychology/Psychologie Canadienne, 58(1), 7-19. doi: 10.1037/cap0000096

Cuijpers, P., Ebert, D. D., Acarturk, C., Andersson, G., \& Cristea, I. A. (2016). Personalized psychotherapy for adult depression: A meta-analytic review. Behavior Therapy, 47, 966-980. doi: 10.1016/j.beth.2016.04.007

Cuijpers, P., Van Straten, A., Warmerdam, L., \& Smits, N.
(2008). Characteristics of effective psychological treatments of depression: A metaregression analysis. Psychotherapy Research, 18(2), 225-236. doi: 10.1080/10503300701442027

Daňsová, P., Masopustová, Z., Hanáčková, V., Kicková, K., \& Korábová, I. (2016). Metoda Patient Health Questionnaire-9: Česká verze [Patient Health Questionnaire-9 method: Czech version]. Ceskoslovenska Psychologie, 60(5), 468-481.

Dattilio, F. M., Edwards, D. J. a, \& Fishman, D. B. (2010). Case studies within a mixed methods paradigm: Toward a resolution of the alienation between researcher and practitioner in psychotherapy research. Psychotherapy, 47(4), 427-441. doi: 10.1037/a0021181

Dimaggio, G., Fiore, D., Salvatore, G., \& Carcione, A. (2007). Dialogical relationship patterns in narcissistic personalities: Session analysis and treatment implications. Journal of Constructivist Psychology, 20(1), 23-51. doi: 10.1080/ 10720530600992741

Edwards, D. J. (2010). Using systematic case studies to investigate therapist responsiveness: Examples from a case series of PTSD treatments. Pragmatic Case Studies in Psychotherapy, 6(4), 255-275. doi: 10.14713/pcsp.v6i4.1047

Elliott, R. (1986). Interpersonal Process Recall (IPR) as a psychotherapy process research method. In L. Greenberg \& W. M. Pinsof (Eds.), The psychotherapeutic process (pp. 503 527). New York, NY: Guilford.

Elliott, R. (1993). Helpful Aspects of Therapy form (HAT). Retrieved from: http://www.experiential-researchers.org/instruments/elliott/hat.html

Elliott, R. (2002). Hermeneutic single-case efficacy design. Psychotherapy Research, 12(1), 1-21. doi: 10.1080/713869614

Elliott, R., \& Rodgers, B. (2008). Client Change Interview Schedule (v5). Avaialble from: https://drive.google. com/file/d/0B4QhybeF75vseWRYMjIFQVFRWIU

Flückiger, C., Del Re, A. C., Wampold, B. E., \& Horvath, A. O. (2018). The alliance in adult psychotherapy: A meta-analytic synthesis. Psychotherapy, 55(4), 316-340. doi: 10.1037 /pst0000172

Hatcher, R. L. (2010). Alliance theory and measurement. In J. C. Muran \& J. P. Barber (Eds.), The therapeutic alliance. An evidence-based guide to practise (pp. 7-28). New York, London: The Guilford Press.

Hatcher, R. L. (2015). Interpersonal competencies: Responsiveness, technique, and training in psychotherapy. American Psychologist, 70(8), 747-757. doi: 10.1037/a0039803

Horvath, A. O., Del Re, A. C., Flückiger, C., \& Symonds, D. (2011). Alliance in individual psychotherapy. Psychotherapy, 48(1), 9-16. doi: 10.1037/a0022186

Jacobson, N. S., \& Truax, P. (1991). Clinical significance: A statistical approach to defining meaningful change in psychotherapy research. Journal of Consulting and Clinical Psychology, 59(1), 12-19. doi: 10.1037/0022-006X.59.1.12

Janse, P., Boezen-Hilberdink, L., van Dijk, M. K., Verbraak, M. J. P. M., \& Hutschemaekers, G. J. M. (2014). Measuring feedback from clients. European Journal of Psychological Assessment, 30, 86-92. doi: 10.1027/1015-5759/a000172

Juhová, D., Řiháček, T., Cígler, H., Dubovská, E., Saic, M., Černý, M., ... Evans, C. (2018). Czech adaptation of the CORE-OM: Selected psychometric properties. Ceskoslovenska Psychologie, 62(1), 59-74.

Kramer, U., \& Stiles, W. B. (2015). The responsiveness problem in psychotherapy: A review of proposed solutions. Clinical Psychology: Science and Practice, 22(3), 277-295. doi: $10.1111 /$ cpsp. 12107 
Kroenke, K., \& Spitzer, R. L. (2002). The PHQ-9: A new depression diagnostic and severity measure. Psychiatric Annals, 32, 509-521. doi: 10.3928/0048-5713-20020901-06

Lambert, M. J. (2013). The efficacy and effectiveness of psychotherapy. In M. J. Lambert (Ed.), Bergin and Garfield's handbook of psychotherapy and behavior change (6th ed., pp. 169-218). Hoboken, NJ: John Wiley.

Leichsenring, F., \& Schauenburg, H. (2014). Empirically supported methods of short-term psychodynamic therapy in depression - Towards an evidence-based unified protocol. Journal of Affective Disorders, 169, 128-143. doi: 10.1016/j.jad.2014.08.007

Lemmens, L. H. J. M., Müller, V. N. L. S., Arntz, A., \& Huibers, M. J. H. (2016). Review: Mechanisms of change in psychotherapy for depression: An empirical update and evaluation of research aimed at identifying psychological mediators. Clinical Psychology Review, 50, 95-107. doi: 10.1016/j.cpr.2016.09.00

Llewelyn, S. (1988). Psychological therapy as viewed by clients and therapists. British Journal of Clinical Psychology, 27(3), 223-238.

Mander, J., Schlarb, A., Teufel, M., Keller, F., Hautzinger, M., Zipfel, S., ... Sammet, I. (2015). The individual therapy process questionnaire: Development and validation of a revised measure to evaluate general change mechanisms in psychotherapy. Clinical Psychology \& Psychotherapy, 22(4), 328-345. doi: 10.1002/cpp.1892

Manea, L., Gilbody, S., \& McMillan, D. (2012). Optimal cutoff score for diagnosing depression with the Patient Health Questionnaire (PHQ-9): A meta-analysis. Canadian Medical Association Journal, 184(3), 191-196. doi: 10.1503/cmaj. 110829

Mcleod, J. (2010). Case study research in counselling and psychotherapy. London: Sage.

Munder, T., Wilmers, F., Leonhart, R., Linster, H. W., \& Barth, J. (2009). Working Alliance Inventory-Short Revised (WAISR): Psychometric properties in outpatients and inpatients. Clinical Psychology \& Psychotherapy, 17, 231-239. doi: 10.1002/cpp.658

Muran, J. C., Safran, J. D., Gorman, B. S., Samstag, L. W., Eubanks-Carter, C., \& Winston, A. (2009). The relationship of early alliance ruptures and their resolution to process and outcome in three time-limited psychotherapies for personality disorders. Psychotherapy, 46(2), 233-248. doi: 10.1037/a0016085

Norcross, J. C., Krebs, P. M., \& Prochaska, J. O. (2011). Stages of change. Journal of Clinical Psychology, 67, 143-154. doi: $10.1002 /$ jclp.20758

Řiháček, T., \& Danelová, E. (2016). The journey of an integrationist: A grounded theory analysis. Psychotherapy, 53(1), 78-89. doi: $10.1037 /$ pst0000040

Ronnestad, M. H., \& Skovholt, T. M. (2013). The developing practitioner: Growth and stagnation of therapists and counselors. New York: Routledge.

Roos, J., \& Werbart, A. (2013). Therapist and relationship factors influencing dropout from individual psychotherapy: A literature review. Psychotherapy Research, 23(4), 394-418.

Safran, J. D., \& Muran, J. C. (1998). The therapeutic alliance in brief psychotherapy: General principles. In J. D. Safran \& J. C. Muran (Eds.), The therapeutic alliance in brief psychotherapy (pp. 227-229). Washington, DC: American Psychological Association.
Safran, J. D., \& Muran, J. C. (2000). Resolving therapeutic alliance ruptures: Diversity and integration. Journal of Clinical Psychology, 56(2), 233-243.

Safran, J. D., \& Muran, J. C. (2006). Has the concept of the therapeutic alliance outlived its usefulness? Psychotherapy: Theory, research, practice, training, 43(3), 286-291. doi: 10.1037/0033-3204.43.3.286

Schauenburg, H., \& Strack, M. (1999). Measuring psychotherapeutic change with the Symptom Checklist SCL 90 R. Psychotherapy and Psychosomatics, 68(4), 199-206. doi: $10.1159 / 000012333$

Sharf, J., Primavera, L. H., \& Diener, M. J. (2010). Dropout and therapeutic alliance: A meta-analysis of adult individual psychotherapy. Psychotherapy: Theory, Research, Practice, Training, 47(4), 637-645. doi: 10.1037/a0021175

Stiles, W. B. (2009). Responsiveness as an obstacle for psychotherapy outcome research: It's worse than you think. Clinical Psychology: Science and Practice, 16(1), 86-91. doi: 10.1111/j.1468-2850.2009.01148.x

Stiles, W. B., Caro Gabalda, I., \& Ribeiro, E. (2016). Exceeding the therapeutic zone of proximal development as a clinical error. Psychotherapy, 53(3), 268-272. doi: 10.1037/ pst0000061

Stiles, W. B., \& Goldsmith, J. Z. (2010). The alliance over time. In J. C. Muran \& J. P. Barber (Eds.), The therapeutic alliance. An evidence-based guide to practise (pp. 44-62). New York, London: The Guilford Press.

Swift, J. K., \& Greenberg, R. P. (2012). Premature discontinuation in adult psychotherapy: A meta-analysis. Journal of Consulting and Clinical Psychology, 80(4), 547-559. doi: 10.1037/a0028226

Swift, J. K., \& Greenberg, R. P. (2014). A treatment by disorder meta-analysis of dropout from psychotherapy. Journal of Psychotherapy Integration, 24(3), 193-207. doi: 10.1037/ a0037512

Swift, J. K., Greenberg, R. P., Whipple, J. L., \& Kominiak, N. (2012). Practice recommendations for reducing premature termination in therapy. Professional Psychology: Research and Practice, 43(4), 379-387. doi: 10.1037/a0028291

Swift, J. K., Tompkins, K. A., \& Parkin, S. R. (2017). Understanding the client's perspective of helpful and hindering events in psychotherapy sessions: A micro-process approach. Journal of Clinical Psychology, 73(11), 1543-1555. doi: 10.1002/jclp.22531

Timulák, L. (2010). Significant events in psychotherapy: An update of research findings. Psychology and Psychotherapy: Theory, Research and Practice, 83(4), 421-447. doi: 10.1348/147608310X499404

Westerman, M. A., \& Muran, J. C. (2017). Investigating an approach to the alliance based on interpersonal defense theory. Psychotherapy Research, 27(5), 620-641. doi: 10.1080/ 10503307.2016.1152407

Williams, D. C., \& Levitt, H. M. (2007). Principles for facilitating agency in psychotherapy. Psychotherapy Research, 17(1), 66-82. doi: 10.1080/10503300500469098

World Health Organization (WHO). (1992). The ICD-10 classification of mental and behavioural disorders: Clinical descriptions and diagnostic guidelines. Geneva: World Health Organization.

Zimmerman, M., McGlinchey, J. B., Posternak, M. A., Friedman, M., Attiullah, N., \& Boerescu, D. (2006). How should remission from depression be defined? The depressed patient's perspective. American Journal of Psychiatry, 163, 148-150. doi: 10.1176/appi.ajp.163.1.148 